\title{
Management of Technology Transfer in Organization Using OpenMes Software
}

\author{
Crenguta Ileana SINISI ${ }^{\star}$
}

\begin{tabular}{l}
\hline \multicolumn{1}{c}{ A R T I C L E I N F O } \\
\hline Article history: \\
Accepted April 2021 \\
Available online May 2021 \\
\hline JEL Classification \\
M11, M15, M20, 0 32, 033 \\
Keywords: \\
Automation, Mechanics, Applied \\
science, Industry, Knowledge
\end{tabular}

\begin{abstract}
A B S T R A C T
In order to provide components and wheels that are actually the simplest terms of performance, durability, and functionality, you may wish to take a position in both parts of development and testing. Each product, component or even wheel, is intended within the corporate Mechrom, then is getting developed and tested inside the mother company, Campagnolo, on this case, the identical Campagnolo engineer that develop the new products, elaborate what is necessary to test the performance, durability or even more, quality of their own products.
\end{abstract}

\section{Introduction}

Innovation is more like a technological change that outperforms a previous apply. In order to steer or sustain with innovations, most of the managers must be compelled to concentrate heavily on the innovation network, which needs a verry deep understanding of the complexness of innovation. When a technology goes through a big transformation part and yields a productive innovation, it becomes an excellent learning expertise, not just for the parent business however different industries yet. Massive innovations area unit usually the result of knowledge domain networking while technological sectors, along with combination of implicit and specific data information. [9]

Networking is now necessarily, however network integration is in this case the key to success for classy innovation. The Social-economic zones, technology corridors, trade agreements, or technology clusters unit of measurement it may be on different ways within to encourage structure networking and crossfunctional innovations. In over eighty years of innovation, quality and sporting success, Campagnolo is also a premium organization that has preserved its name throughout all over the world. Our long history, that has helped tons since starting and development of recent athletics, is impressed by the innovative spirit, it's become Associate in Nursing integral an element of our polymer society. Continuous studies for performance and maximum quality, along with the Italian ethernet taste for design, style and shape, makes the Campagnolo world and its own products stand enter all its aspects. Service and even customer care emphasize continued pursuit of excellence, guaranteeing that every customer will find an unrivaled ally in Campagnolo's passion for cycling.

The Mechrom 1 product range includes both Super Record, Record, Chorus, and 11-speed Potenza 11 and Veloce 10-speed sets. Since 2011, the range has also been added to the lightest racing bike market electronics groups: Super Record EPS, Record EPS and Chorus EPS. The continuous process of innovation in Campagnolo technologies pursues solutions that, lately, have been leding to the miniaturization of our electronic components, the introduction of power units with some of the frame and also the optimization of changes in both ways of both accuracy and speed. Called EPS (Electronic Power Systems) of these systems are produced during special units named Mechrom 1 units in Mărăcineni. But this can be not all, Campagnolo is additionally one of the primary cycling world to introduce the new concept of "fully assembled wheel". In the late eighties, Shamal was the first "ready-to-use" wheel on the market, proudly produced within the Mechrom 2 units in Curtişoara. Today, Campagnolo offers for the cycling fans round the world wheel for road bikes made out of carbon, aluminum and even in aluminum-carbon.

Solutions that applied to the wants of the users, starting from a low profile climbers to a very highprofile wheels, meant to optimize aerodynamic penetration and supply maximum benefits while using conditions of a non-only use at high speeds, but also used during a speed or triathlon race. The Campagnolo range is best additionally complemented by its mid-range wheels, with a wonderful process of training and get solution or mixed stage, therefore the bike setting requires maximum versatility. The production of 
bicycle wheels in the Romanian Campagnolo industry is divided between the two factories. Mechrom 1 has more than 10 years of experience in the production of carbon and aluminum-carbon wheels, with plenty of proprietary technologies. Mechrom2 is more focused on the production of fully assembled wheels, based on the latest technologies here are produced the best aluminum wheels in the market.

\section{Mission, Vision, Objectives}

The company produces products with high technology, innovation and design but also with consistent quality over a long life of the product. Offers the customer a prompt and quality service. The various products are based on a differentiated image activity, according to our vision. Personal development is supported by a steady promotion of responsibility and a clear direction of sharing information to achieve goals. Being a leader in high-end product classes for all cycling applications with a distinctive brand that conveys entertainment. Objectives:

Increased sales of bicycle components by $15 \%$ in the next 3 months;

- Opening of a new point of work in the next 2 years in order to increase the production capacity of the company;

- Increasing the efficiency of the production lines in the next 3 months by $10 \%$.

- Implementation of a new software for the production of carbon fiber circles by the beginning of July. In particular, the company collaborates with suppliers regarding the parts required to manufacture bicycle components. Suppliers can intervene by threatening to increase their prices, but mechrom Industry does not want to interfere in the activity of the suppliers, but only wants to ensure that they will comply with the standards imposed by the company. Suppliers play a very important role because they represent in fact the interface between the product and the manufacturer. and they have to be very well motivated because otherwise they can go towards the more intense promotion of a competitor of Mechrom Industry. The company's suppliers have a large bargaining power, based on the specialized profile of the activity, negotiating within a system based on the minimum lot to ensure their profit margin. [17]

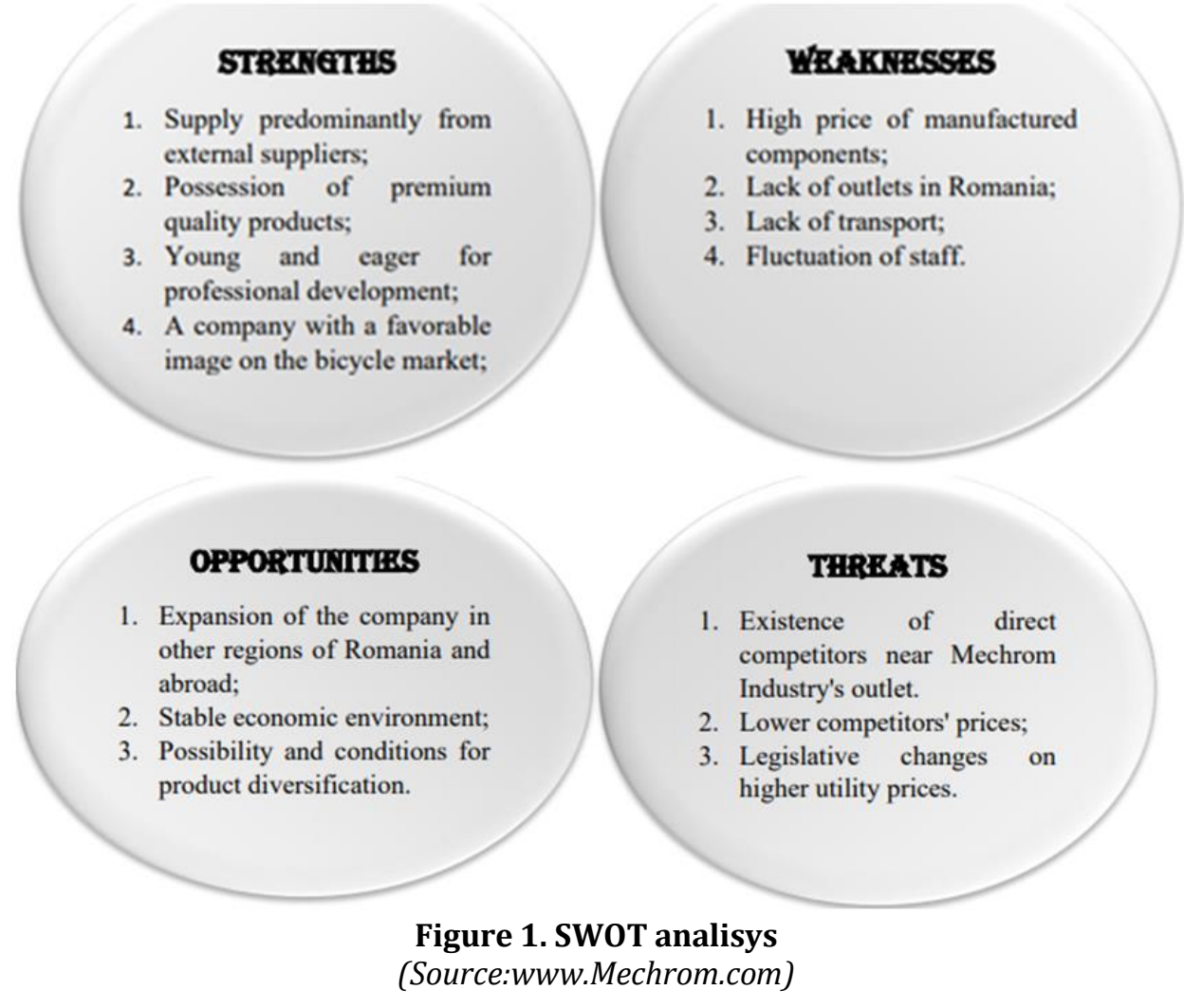

\subsection{Product portfolio and company promotion}

Mechrom's carbon wheels are unique: light, aerodynamic and smooth running, with the best braking performance for a most unique travel experience. The technical characteristics, the quality and the carbon workmanship make them some of the best carbon wheels for racing bikes. The range of carbon wheels produced in Mechrom offers solutions to meet all your needs, The Bora family, completely updated, offers a wide range of deep and medium profile carbon wheels. The rim width has been increased to better fit the new tires available on the market, thus ensuring maximum safety, aerodynamic comfort. [7] 
The new AC3 textured brake surface guarantees the rider excellent braking in all weather conditions. Bora carbon wheels are available for both tubular and ratchet tires. Super Record '12x2 Speed disc brake set, is the highest expression of Campagnolo technology and evolution. It is perfect for cyclists who want to equip their own bicycle with the best market in terms of performance and distinctiveness. Ergo-power controls, they are even more ergonomic due to the unique shape of the levers that allows a better functioning.

The new shaft with two-arm coupling is a step forward in terms of rigidity, constantly maintaining the technologies and advantages characteristic of the Super Record.

Super Record 12 speed gears, features thinner sprockets, tighter spaces and space saving dimensions that are the same as those with 11 speed sprockets, meeting the needs of all with just two tapes. The addition of the twelfth gear pinion allows for a linear change or descent through a single tooth, until the seventh sheet, allowing the rider to find the perfect ratio for any situation.

Electronic transmission system EPS, a traction system that has reached levels of performance and functionality that were previously unthinkable. All three EPS groups promise minute accuracy, speed and fluidity of changing speeds even under voltage: Super Record EPS, Record EPS and Chorus EPS. [6]

\subsection{The promotion of Mechrom on the market is closely related to the promotion of the parent company, Campagnolo!}

Since the company was founded more than 80 years ago, Campagnolo products have always been a favourite component of huge names in cycling. Over the years, champions like Coppi, Gimondi and Merckx have relied on the standard and accuracy of Campagnolo that has accompanied them to their unforgettable victories. This trend has continued to the present day, only if many of the most effective teams and top athletes have chosen the identical qualities and performances, selected year after year by the best champions of the past.

This year we see an oversized number of teams that still use the Italian brand and plenty of new teams that want to win are going to be a part of the Campagnolo family. With 3 teams within the UCI World Tour, 3 Pro-continental, 16 Continental, $18 \mathrm{U}-23$ and lots of more, it's very clear that much of the cycling world has decided to return to Campagnolo so as to enjoy itself.

The technical advantages, reliability and performance needed to win at any level. as long as teams and athletes round the world, the most effective male and feminine champions in both road racing and triathlon events choose Campagnolo products, we will honestly say that the corporate could be a benchmark for excellent cycling components.

\section{Anticipating the needs of customers and permanently adapting the offer to them}

Bicycle customers' needs are important for both the Campagnolo parent company, but especially for the Mechrom Industry Company, as the latter has to improve the production process so that the finished product can meet expectations. Most of the clients of Campagnolo C. [4]

Company targets are professional cyclists, and their expectations regarding bicycles are very high, which is the main reason why Campagnolo along with Mechrom Industry in Romania, is in a permanent way of trying to adapt to the strain of the market. Whether it's wheels, brakes or even transmission components, at Campagnolo it always starts with ower premise that each product you design will be the first and foremost a security device starting before it becomes a performance tool.

So as to supply its components and wheels that are the most effective in direct terms of performance, durability and functionality, you would like to see lots in both development and testing process.

Every product of the company, either component or wheel, is intended within the corporate Mechrom, then developed and tested for multiple times inside the mother company, Campagnolo.

After the Mechrom Industry produces and the mandatory components, they're sent to the Campagnolo company, and that they are again tested within the testing departments within the corporate, a department dedicated to supporting the complete development activity of the corporate. This department is the one that is provided with state-of-the-art technologies, a number of which are developed on internally to satisfy the best technological needs of the corporate itself. As Campagnolo bikes are addressed for professional cyclists, and therefore the needs and expectations are way up high, that's a main reason for Mechrom Industry to often up to now with the strain of shoppers, and is persuasing trying to adapt to them, so Campagnolo bikes meet expectations.

In the upper case, the identical Campagnolo engineers that were meant to develop more new products, elaborate daily what's necessary in order to check the performance, durability and quality of the products themselves. Thanks for continuous improvement, Campagnolo constantly monitors customer behavior, their new preferences and the fact that new products are repeatedly subjected to testing cycles with the precise purpose of ensuring the identical best qualities identified during the process and development stage are maintained throughout it and production at the industrial level. 


\subsection{Technology transfer from SOFTWHEELS TO OPENMES}

Mechrom Industry currently uses software to produce bicycle hoops called Softwheels, but we want to show you how it will be replaced by the new software that brings improvements to this process, called OpenMes. In the first part we will show how the Softwheels software is presented and what are the stages through which the circles are produced. [21]

For a carbon circle to be worked, step 1 is what we call planning (which is done within the logistics department). The planners work in a program called BAAN, which manages everything related to production orders, the necessary quantities and existing stocks of material. They, together with the staff from Italy, determine the quantities of materials and products to be manufactured for the next period (the principle is used just in time to use as efficiently as possible the space available in the warehouse). [17]

The second software currently used is SoftWheels. It is operated by production staff to manufacture the hoops and be able to have a traceability of operations. In order to be able to produce a circle, 3 production lines are involved, briefly named 910, 912 and 913.

- 910 is the line that deals with carbon fiber rolling.

- 912 is the line that deals with mechanical processing.

- 913 is the line that deals with cutting and packing carbon fiber.

\subsection{Sheet cutting and packaging}

The carbon fiber cutting phase is the activity aimed at obtaining the strips that will be used for modeling the carbon fiber circles starting from the raw material rolls. Starting from Baan, after creating the circle making ODP and transferring it to SoftWheels, the production follows these steps:

Select the manufacturing ODP they want to work on $\rightarrow$ procure the carbon fiber sheet (raw material) $\rightarrow$ select the operator who will work $\rightarrow$ open / select the cutting plan and set the parameters $\rightarrow$ cut the sheet $\rightarrow$ pack the resulting strips in bags (kit) $\rightarrow$ enter the amount of material cut and the batch of raw material used $\rightarrow$ print the barcode (a label containing all the data of the resulting product, eg: operator, working time, raw material lot code etc) and stick on the kit $\rightarrow$ declare the end of the activity. For kits, the operation starts from Plotter by: creating the kits, printing the production order label (barcode), completing the production order and declaring the end of the activity. To ensure the same functionality as Softwheels, OpenMes will need to manage the traceability of this production process, recording the association between batches of raw materials used and batches of sheets produced. [18]

In addition, OpenMes is required to record the actual hours recorded by individual operators on the processed labels. For OpenMes there will be some differences in this stage such as:

- After the circle making ODP has been transferred to OpenMes, the carbon fiber cutting order will be created here, the order will be selected and the start of the activity will be declared, followed by the same steps from setting the parameters to packing them.

- The next step is to declare the end of the cutting activity in the system, followed by entering the amount of cut materials and the batch of origin, ending with the printing of the label.

- For kits, after creating them, close the production order, then print the label.

- This phase ends by closing the circle making ODP only after the needles and the rest of the phases have been completed. [17]

\subsection{Preparing the kit}

A kit is a set of foils that must be used in the rolling phase to produce a circle or part of it. In general, the following are used to produce a carbon fiber rim:

- 1 kit bigoli

- 1 leather kit

- 1 hat kit

This is essentially a selection operation from the container containing the monofilament envelopes relating to an order of laminating $\mathrm{n}$ foils to obtain $\mathrm{n}$ sets of separate foils.

For this operation must be managed:

- Traceability

- Operating time

- Study of data related to the container

The current operating procedure is performed in motion with a radio frequency optical gun and involves the following steps:

It starts by using the optical reader to authenticate the operator (by reading the badge / mobile badge) $\rightarrow$ selecting the container (by reading the barcodes) $\rightarrow$ choosing the sheets and managing traceability (by reading the barcodes) $\rightarrow$ in SoftWheel the end will be declared activity $\rightarrow$ database processing $\rightarrow$ completion of the activity.

In the future, it is desired that the first half of the process be integrated directly into the program so as not to be obviously separated from a database. The new operating procedure does not involve moving, but from a fixed OpenMES location, and involves the following steps: 
- $\quad$ Authentication (if not previously done)

- Selecting the work order for preparing the kit and declaring the start of the activity $\bullet$ Generating container labels (the current working hypothesis is that they become "disposable", ie they are not reused)

- Choice of foils. Entering the batch by reading the barcodes will only be required for foils with more than one batch

- Declaring the end of the activity

- Database processing. program. [16]

In short, after importing the data into OpenMes, all these activities will be managed directly in the

\section{From softwheels to openmes}

For OpenMes, the steps will follow a similar structure, namely:

After the initial operations in Baan and transferring the order to OpenMes $\rightarrow$ the barcode of the circle corresponding to the odp will be printed $\rightarrow$ creation of the laminar odp batch $\rightarrow$ manual planning and allocation of the batch (composed of creating the rolling sequence and partitioning the cutting station) $\rightarrow$ station, bigoli and laminae will be made, the bar code of the circle will be printed and printed $\rightarrow$ returning to the system, the rolling batch will be selected and the work process will start $\rightarrow$ selecting the cappelli kit and declaring the series for traceability (by reading barcodes) $\rightarrow$ data processing $\rightarrow$ the end of the activity is declared.

The data to be entered are the same, but there are the following differences: - Data will not be uploaded offline at the end of the day, but in real time on the single workstation;

- $\quad$ For this purpose, unique touch screen computers will be used, which must be used by operators in tablet mode;

- The terminals will be used both to allow operators to enter information in real time and to provide the information collected for the purpose of carrying out their activities and to interact with colleagues: in particular, it must be possible to view multimedia files related to the article in deployment and to send requests to staff for line management;

- The system must provide the department manager with a tool for managing rolling orders at individual stations.

\section{Company image on the market}

The image of Mechrom starts from the first contact that it has with the clients, especially by the quality of the manufactured products and of the offered services and from the image formed in front of the employees. The image of the company towards stakeholders is defined by characteristics such as: professionalism, seriousness, quality superior of the offered products etc. Mechrom Industry products have a superior quality which gives them an excellent image from this point of view by paying attention to the details offered on the production process and the materials used, which attracts the most customers of the company.

Also, the history behind the name of the Campagnolo mother company is another reason why they are attracted to their products, giving them an image of tradition, belonging to a community and age / stability over time. [12]

Another component that plays an important role in the company's image is the professionalism of the suppliers and distributors that Mechrom works with, ensuring that the materials needed for the production and transport of finished products to customers are made on time. In front of the employees, the company has a favorable image through the organizational culture created, by respecting the rights and obligations towards them, by involving in the continuous improvement of the manufacturing processes and the working conditions in which they carry out their activity, the timely fulfillment of the projects developed, etc.

An aspect that demonstrates the stability of the company is its financial situation, which has registered a steady profit in recent years. The management of SC Mechrom Industry SRL is made up of both Italians who came from the parent company Campagnolo as well as Romanians. This shows that the management is willing to listen and know the particularities of the local market.

The public opinion of the company in the area where it owns the factories is a good one, often meetings and meetings with local administration institutions designed to encourage the employment available within the company or its involvement in social campaigns meant to support the community (such as giving gifts and financial aid to children in local schools). [11]

The company produces products with high technology, innovation and design but also with consistent quality over a long life of the product. Offers the customer a prompt and quality service. The various products are based on a differentiated image activity, according to our vision.

Mechrom 1, is a constant leader in the world of components and wheels for race and triathlon bikes. A multinational company that offers innovative avant-garde products, technology leader for the entire cycling industry. 
In order to develop and maintain its role on this market, Mechrom 1, with a family of 562 people, always seeks talents that have the same vision and want to develop personally and professionally.

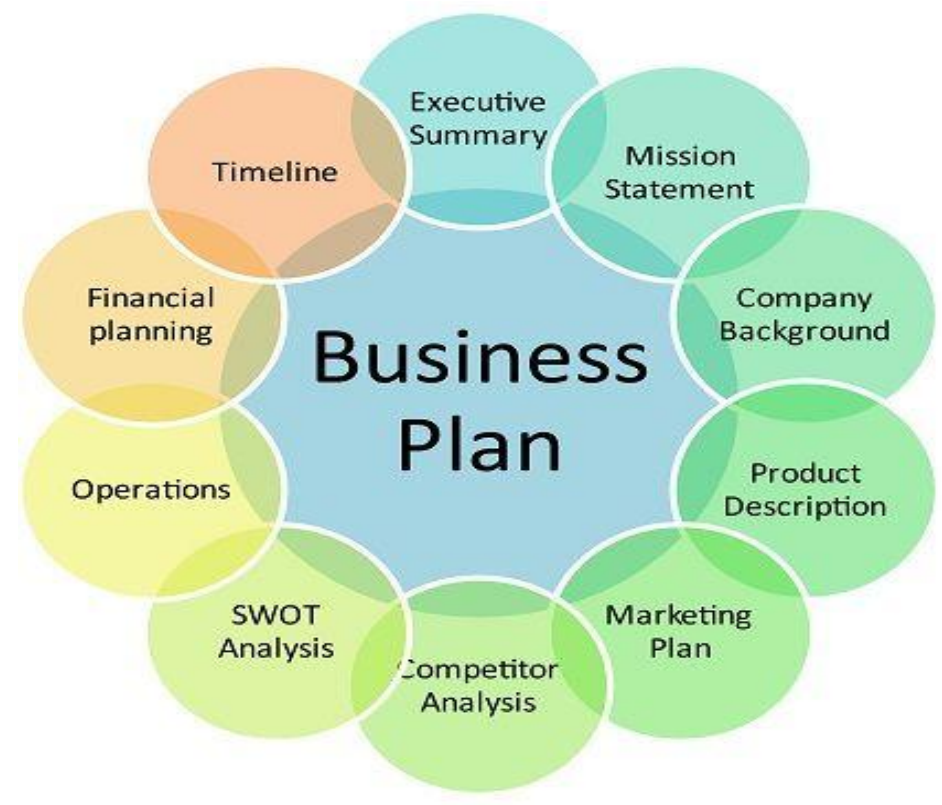

Figure 3. Business plan

(Sourse: https://www. marketing.com/)

In the post-current culture of cycling and sports like marathon, with an all-encompassing practice inside the Western world, Campagnolo offers segments through two creation units situated in Romania. Campagnolo items are more uncommon by their consideration, innovation, advancement and cycles utilized in each stage, from origination, improvement, creation and testing. During the 1950s, Campagnolo was the essential society that present the idea of the whole gathering, at that point the essential organization to consider the race bicycle dashing train even as one component, made out of segments that needs to cooperate in wonderful advantageous interaction.Bicycle customers' needs are important for both the Campagnolo parent company, but especially for the Mechrom Industry company, as the latter has to improve the production process so that the finished product can meet expectations. [9]

The greater part of the customers of Campagnolo organization are proficient cyclists, and their assumptions about bikes are extremely high, which is the reason Campagnolo alongside Mechrom Industry in Romania, is reliably attempting to adjust to market's requests. Regardless of whether it's wheels, brakes or transmission parts, at Campagnolo it generally begins with the reason that every item you configuration is as a matter of first importance a security gadget before it turns into an exhibition device. To lead or support with advancements, supervisors should focus vigorously on the development organization, which needs a profound comprehension of the intricacy of development. Cooperation might be an imperative wellspring of advancement. Advancements are progressively dropped at the market by organizations of associations, chosen per their relative benefits, and working in an exceptionally planned way. At the point when innovation goes through a major change stage and yields an effective development, it turns into a legitimate learning experience, for the parent business as well as different ventures in like manner. [4]

Huge advancements are by and large the consequences of intra-and interdisciplinary systems administration among mechanical areas, alongside the combination of understood and express information. Systems administration is required, yet network mix is that the way to progress for complex advancement. Social-monetary zones, innovation passages, economic alliance, and innovation bunches are a few different ways to empower hierarchical systems administration and cross-practical advancements.

\section{Conclusion}

Creative Thinking While both Amabile and Gardner assert that thinking might be a key aspect of the creative process, they address this subject at a high level.

Amabile suggests that key aspects of creativity are:

- Comfort in disagreeing with others and trying solutions that depart from the established order.

- Combining knowledge from previously disparate fields.

- Ability to persevere through difficult problems and dry spells.

- Ability to step far from a trial and return later with a fresh perspective ( "incubation"). 
Considerable research has built up over the last 30 - 40 years at four specific approaches to levels-ofanalysis - the individual, the work team, organizational, and multi-level approaches - across several disciplines within the management sciences. this review aims to comprehensively integrate these findings, but especially those published over the last decade, and to present key directions for future research.

There has been an exponential growth within the quantity of papers published on creativity and innovation generally, and specifically on workplace creativity and innovation over recent years. We propose the subsequent integrative definition of inovation and creativity:" Creativity and innovation at work are the process, outcomes, and products of attempts to develop and introduce new and improved ways of doing things." The creativity stage of this process refers to idea generation, and innovation to a subsequent stage of implementing the best ideas toward better procedures or practices or products. In the post-current culture of cycling and marathon, with an old practice inside the Western world, Campagnolo make parts, gatherings and wheels through two creation units situated in Romania. Campagnolo items are recognized by their consideration, innovation, advancement and cycles utilized in each stage, from origination, improvement, creation and testing.

Activities performed with the help of the optical reader (not performed in a program, a separate database is kept which is then imported into the program).

In more than eighty years of advancement, quality and donning achievement, Campagnolo might be a top notch brand that protects its standing all through the planet. Our long history, which has helped a lot to the birth and advancement of late cycling, is propelled by the creative soul, it's become a fundamental a piece of our DNA society. [22]

Persistent investigate for execution and most extreme quality, joined with the intrinsic Italian preference for style and shape, makes the Campagnolo world and its items stand move into every one of its viewpoints. Administration and client care stress proceeded with quest for greatness, ensuring each client tracking down an unmatched partner in Campagnolo's enthusiasm for cycling. In the post-current culture of cycling and marathon, with an extended custom inside the Western world, Campagnolo produces segments, gatherings and wheels through two creation units situated in Romania. [15]

Campagnolo items are recognized by their consideration, designing, advancement and cycles utilized in each stage, from origination, improvement, creation and testing. During the 1950s, Campagnolo was the essential to present the idea of the entire gathering, at that point the essential organization to consider the race bicycle hustling train as one component, made out of parts that need to figure together in wonderful beneficial interaction

\section{References}

1. Anderson, E. W., \& Sullivan, M. W., (1993). The antecedents and consequences of customer satisfaction for firms. Marketing science, 12(2), 125-143.

2. Audretsch, D. B., (2007). The entrepreneurial society. University Press on Demand.

3. Audretsch, D. B., (2014). From the entrepreneurial university to the university for the entrepreneurial society. The Journal of Technology Transfer, University of Massachusetts, 39(3), 313-32.

4. Audretsch, D. B., \& Lehmann, E. E. (2005). Do University policies make a difference?. Research Policy, 34(3), 343-34.

5. Audretsch, D. B., Hülsbeck, M., \& Lehmann, E. E. (2012). Regional competitiveness, university spillovers, and entrepreneurial activity. Small Business Economics, 39(3), 587-601.

6. Audretsch, D. B., Keilbach, M. C., \& Lehmann, E. E., (2006). Entrepreneurship and economic growth, Oxford University Press.

7. Audretsch, D. B., Lehmann, E. E., \& Wright, M., (2014). Technology transfer in a global economy. The Journal of Technology Transfer, 39(3), 301-312.

8. Audretsch, D., Lehmann, E., \& Warning, S., (2004). University Spillovers and New Firm Location. Max Planck Institute of Economics, Entrepreneurship, Growth and Public Policy Group.

9. Bercovitz, J., Feldman, M., Feller, I., \& Burton, R., (2001). Organizational structure as a determinant of academic patent and licensing behavior: An exploratory study of Duke, Johns Hopkins, and Pennsylvania State Universities. The Journal of Technology Transfer, 26(1), 21-35.

10. Casson, M., (1990). Global Corporate R\&D Strategy: A Systems View. University of Rosenberg.

11. Casson, M.; Pearce, R. D.; Singh, (1992). Business Culture and International, University of Montreal.

12. Chan, A. P., \& Chan, A. P. (2004). Key performance indicators for measuring construction success. Benchmarking: an international journal, Western University.

13. Dan, M. C. (2012). Clusterele inovative: o soluţie pentru dezvoltarea economică a României. Economie teoretică şi aplicată, 19(9) Academia de Studii Economice, Bucuresti, 574.

14. Imai, M., (2004). Kaizen: the key to Japan's competitive success. 1986. DE WIT, B.; MEYER, R. Strategy: Process, Content, Context. An international perspective. Minneapolis/St. Paul: West Publishing Company.

15. Möller, K., (2010). Sense-making and agenda construction in emerging business networks - How to direct radical innovation. Industrial Marketing Management, Harvard University 39(3), 361-371

16. Palan, Ronen and Jason Abbott., (1996). State Strategies in the Global Political Economy, London: Pinter.

17. Rosenau, James (2010). Distant Proximities: Dynamics Beyond Globalisation, Princeton University Press.

18. Rosenberg, Justin (2000). Follies of Globalisation Theory: Polemical Essay, London.

19. Sinisi, C.I. (2017). Management of Technology Transfer in the Context of Globalization, Digital Book.

20. Sinisi, C.I. (2020). Integrarea managementului calității, strategiei și inovării în spațiul economic, Editura Economică, București.

21. Tomescu C.I., (2008). Managementul Inovarii, Ed. SITECH, Craiova.

22. Zoltan J. A., \& Preston, L. (1997). Small and medium-sized enterprises, technology, and globalization: Introduction to a special issue on small and medium-sized enterprises in the global economy. Small Business Economics, 9(1), 1-67. 